Cardiology (32018)

SELF-ASSESSMENT QUESTIONNAIRE

\section{SAQs and answers are ONLINE for RCP Fellows and Collegiate Members}

The SAQs printed in the CME section can only be answered online to achieve external CPD credits. The closing date is 21 September 2007 (midnight GMT).

\section{Change in format}

As announced in the previous issues, SAQs will now follow a best of five format in line with the MRCP(UK) Part 1 exam. Candidates are asked to choose the best answer from five possible answers. The online system, passwords and pass mark will remain the same.

There may be teething problems and we would be grateful if all comments/problems could be sent in via email only:

clinicalmedicine@rcplondon.ac.uk

We recommend that answers are submitted early so that any problems can be resolved before the deadline.

\section{The answering process}

1 To access the questions, log on to the Fellows and Members area www.rcplondon.ac.uk/Members/SAQ (those who have not yet registered will be automatically directed to the registration pages). Please contact the Information Centre if you have lost or forgotten your username or password: infocentre@rcplondon.ac.uk

2 Select: Self assessment

3 At the top of the SAQ page select the current CME question paper

4 Answer all 10 questions in any order, by selecting the best answer

5 Check your answers and change them if you wish to

6 Click on Submit for final marking.

NOTE - after submitting your answers NO changes are possible.

\section{The marking process}

- You must submit the answers before the closing date shown at the top of the screen

- Answers will be marked automatically on the date displayed for that paper

- You can find your marks on the CME page under My past CME papers.

\section{Registering your external CPD credits}

A pass mark of $80 \%$ allows you to claim two external CPD credits. Only the first seven distance-learning credits will be counted as external; the remainder can be claimed as personal credits.

To claim your credits:

- Credits can be recorded using the online diary system. All Clinical Medicine SAQs are listed under External Approved CPD.
1 A 68-year-old man, known to have type 2 diabetes and hypertension, presented with chest tightness of one hour's duration. An ECG showed ST depression and $T$ wave inversion. What was the most appropriate treatment?

(a) Aspirin alone

(b) Aspirin and clopidogrel - intravenous (iv) glycoprotein (GP) llb/llla inhibitors only if ongoing pain

(c) Aspirin and clopidogrel - iv GP Ilb/Illa inhibitors only if troponin levels are raised

(d) Aspirin and iv GP Ilb/llla inhibitors

(e) Aspirin, clopidogrel and iv GP Ilb/Illa inhibitors

2 Which recent trial demonstrated benefit of treatment with a combination of aspirin and clopidogrel in ST elevation myocardial infarction (MI)?
(a) CADILLA
(b) CAPRIE
(c) COMMIT
(d) CURE
(e) ISIS-2

3 What coronary heart disease risk reduction results from taking simvastatin $40 \mathrm{mg} /$ day for three years?
(a) $30 \%$
(b) $40 \%$
(c) $50 \%$
(d) $60 \%$
(e) $70 \%$

4 In a patient who has suffered an acute $\mathrm{MI}$, which of the following is true?

(a) Aspirin $75 \mathrm{mg}$ should be taken for one year and then discontinued

(b) A statin should be prescribed only if the low-density lipoprotein cholesterol is above $4.8 \mathrm{mmol} / \mathrm{l}$

(c) Blood pressure (BP) lowering drugs should be avoided if the systolic BP is below $130 \mathrm{mmHg}$ or the diastolic BP below $80 \mathrm{mmHg}$

(d) Clopidogrel $75 \mathrm{mg}$ should be taken for one year and then discontinued

(e) The annual risk of death without treatment is $30 \%$

5 A 63-year-old man was admitted to hospital with a troponin positive acute coronary syndrome, with $\mathrm{T}$ wave inversion in the leads II, III and aVF of the ECG. He was known to have 
hypertension, hypercholesterolaemia and peptic ulcer disease. Urgent coronary angiography was performed, revealing a tight stenosis in the right coronary artery. What was the safest management plan?

(a) A bare metal stent (BMS) should be implanted and dual antiplatelet therapy (DAPT) continued for life

(b) A BMS should be implanted and DAPT continued for one month

(c) A BMS should be implanted and the patient given aspirin alone for life

(d) A drug-eluting stent (DES) should be implanted and DAPT continued for one month

(e) A DES should be implanted and DAPT continued for 12 months

6 A 45-year-old woman presented with jaw pain. Her dentist recommended wisdom tooth extraction under local anaesthesia. A DES had been implanted three months previously and she was taking aspirin $75 \mathrm{mg}$ od and clopidogrel $75 \mathrm{mg}$ od. What was the best perioperative management of her antiplatelet treatment?

(a) Aspirin should be continued but clopidogrel can safely be stopped

(b) Both aspirin and clopidogrel should be stopped

(c) Clopidogrel should be continued but aspirin can be safely stopped

(d) Neither aspirin nor clopidogrel should be stopped

(e) The aspirin dose should be doubled and the clopidogrel stopped

7 A 45-year-old man presented with a six-month history of exertional breathlessness and an episode of near syncope while running for a bus. He was known to have hypertrophic cardiomyopathy, diagnosed 15 years previously following the incidental detection of a heart murmur. Examination revealed a heart rate of 76 beats per minute (bpm), BP $130 / 70 \mathrm{mmHg}$, a prominent $A$ wave in the venous pulse, a jerky pulse character, a sustained apex beat with a double impulse, an ejection systolic murmur at the left sternal edge increasing with standing from the squatting position. What was the most likely cause of his exertional symptoms?
(a) Aortic stenosis
(b) Left ventricular outflow tract (LVOT) obstruction
(c) Mitral valve prolapse
(d) Pulmonary hypertension
(e) Tricuspid regurgitation

8 A 65-year-old man presented with a one-year history of exertional angina. He had unilateral partial deafness of three years' duration. He was a lifelong non-smoker and was taking no medication. In the family, his sister had a history of deafness and his 35-year-old nephew was being investigated for proteinuria. Examination revealed a few small scaly purple lesions over his trunk, BP $135 / 90 \mathrm{mmHg}$, a regular pulse of 55 bpm, normal venous pressure, normal apex and no murmurs or added sounds on auscultation. Investigations revealed haemoglobin $3.2 \mathrm{~g} / \mathrm{dl}$, erythrocyte sedimentation rate $10 \mathrm{~mm} / 1$ st hour, serum sodium $140 \mathrm{mmol} / \mathrm{l}$, serum potassium $4.1 \mathrm{~mm} / \mathrm{l}$, serum creatinine $130 \mu \mathrm{mol} / \mathrm{l}$, corrected calcium $2.4 \mu \mathrm{mol} / \mathrm{l}$, total protein $64 \mathrm{~g} / \mathrm{l}$, serum electrophoresis normal. An ECG demonstrated sinus rhythm $60 \mathrm{bpm}$, left ventricular hypertrophy (LVH) and inferolateral T wave inversion. An echocardiogram demonstrated concentric LVH (maximum LV wall thickness $1.5 \mathrm{~cm}$ ) with normal systolic function and mild mitral and aortic regurgitation. Coronary angiography revealed minor plaque disease in his proximal left anterior descending artery. What was the most likely diagnosis?

(a) Anderson-Fabry disease

(b) Familial amyloidosis (c) Hypertension

(d) Mitochondrial cytopathy

(e) Noonan syndrome

9 A 55-year-old man collapsed while out shopping. He was successfully resuscitated at the scene. His past history included an anterior MI seven years previously. His current medication included aspirin, atenolol, ramipril and simvastatin. Subsequent investigations showed a troponin $\mathrm{T}$ of $0.7 \mu \mathrm{g} / \mathrm{l}$, LV ejection fraction $35 \%$ on echocardiography, and a coronary arteriogram demonstrated an occluded left anterior descending coronary artery with mild disease in the other epicardial vessels. What was the most appropriate management?

(a) He should be offered an implantable cardioverter defibrillator (ICD) without further testing

(b) He should be offered medical therapy first and then further risk stratified

(c) This patient had a reversible cause for his cardiac arrest and did not require an ICD

(d) This patient required an electrophysiological study prior to being considered for an ICD

(e) This patient should be revascularised and then reassessed for an ICD

10 A 17-year-old athlete presented with an episode of sudden collapse whilst playing football. A 12-lead ECG showed sinus rhythm with LVH and repolarisation changes in the precordial chest leads. An echocardiogram showed asymmetrical septal hypertrophy with an interventricular wall thickness of $32 \mathrm{~mm}$ but no significant gradient in the LVOT at rest. Holter monitoring showed non-sustained ventricular arrhythmia. Questioning revealed that his uncle died suddenly aged 25 . What was the most appropriate management? 
(a) He required further risk stratification with an electrophysiological study

(b) He required further risk stratification with an exercise test before being considered for an ICD

(c) He should be started on amiodarone for his nonsustained ventricular arrhythmia (d) He should be treated with a beta-blocker and reviewed in outpatients

(e) He was at high risk for sudden cardiac death and should be offered an ICD

\section{CME Acute Medicine SAQs}

Answers to the CME SAQs published in Clinical Medicine June 2007

$\begin{array}{llllllllll}\text { Q1 } & \text { Q2 } & \text { Q3 } & \text { Q4 } & \text { Q5 } & \text { Q6 } & \text { Q7 } & \text { Q8 } & \text { Q9 } & \text { Q10 } \\ \text { (c) } & \text { (e) } & \text { (c) } & \text { (b) } & \text { (d) } & \text { (d) } & \text { (e) } & \text { (c) } & \text { (b) } & \text { (b) }\end{array}$

